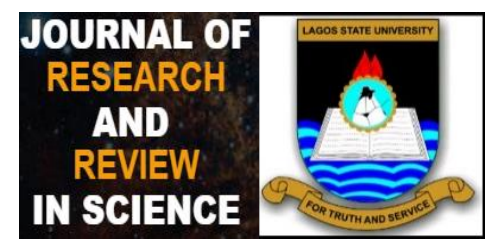

\title{
Dye Sensitized Solar Cells Based on Commelino nudiflora as Sensitizer
}

\author{
AdenikeBoyo ${ }^{1}$, Saheed Oseni', Abdulsalam Ibrahim ${ }^{2}$, "OlasunkanmiKesinro ${ }^{3}$, FatiaAkingbade ${ }^{1}$, \\ MusiliyuOladepo ${ }^{1}$, Paul Okafor $^{1}$, and OluwafemiAbiola ${ }^{1}$
}

${ }^{1}$ Department of Physics, Faculty of Science Lagos State University, Ojo, Nigeria

${ }^{2}$ Department of Chemistry, College of Natural Science

Fountain University, Osogbo, Nigeria

${ }^{3}$ Department of Physics, College of Science and Technology

Oduduwa University, Ipetumodu, Nigeria

\section{Correspondence}

Kesinro Olasunkanmi Razaq, Department of Physics,

Ramon Adedoyin College of Natural Science and Applied Sciences, Oduduwa University, Nigeria.

Email:olakesinro02@gmail.com

\section{Abstract:}

Introduction: The rapid global increase in population and technological advancement has put more pressure on energy provided. This challenge has led to research into alternative forms of energy generation such as solar energy. Recently, dye sensitized solar cells (DSSCs) have been identified ans an emerging alternative to silicon based solar cells due to its low cost of production.

Aim: This research aims to determine the power conversion efficiency of Commelino nudiflora leaves and flowers as sensitizers in DSSCs, experimentally and by simulation.

Materials and Methods: The leaves and flowers of the plants were dried under room temperature before pulverization. The pulverized samples were soaked separately in different solvents and further purified to obtain dye extracts. The characteristics of the dye-sensitized solar cell (DSSC) have been simulated using MATLAB based on titanium dioxide $\left(\mathrm{TiO}_{2}\right)$ by modifying the internal parameters.

Results: The results obtained from the crude extracts indicate that the crude extract from the flower attained the best power conversion efficiency of $0.00389 \%$. also, the purified flower extract attained the best power conversion efficiency of $0.00243 \%$ between the purified extracts. The simulated results show that the crude and purified extracts for the leaves showed a better power conversion efficiency in comparison to the flower extracts. The reduction in efficiency could be attributed to further extraction of compounds that aid absorption of light.

Conclusion: The results obtained indicate that the leaves and flowers of the plant can be used as sensitizers in DSSCs, and further work can be done to enhnace the efficiency.

Keywords: Anthocyanins; crude, electrical properties and optical properties. 


\section{INTRODUCTION}

The quest to reduce the cost of fabrication and maintaining the efficiency of solar cells has intensified in the past years which have resulted into research of alternative forms of solar cells. Presently, dye sensitized solar cells (DSSCs) have been identified as a replacement to silicon based solar cells. Though, the efficiencies and environmental stability of these devices are still low, they can be improved upon for the future. The theoretically predicted power conversion efficiency (PCE) of DSSCs was estimated to be approximately $20 \%$ [1], [2]. This estimation on the PCE has resulted in an extensive research over the years on DSSCs to improve the efficiency and to augment its commercialization. In the late 1960s, it was discovered that electricity can be generated through illuminated organic dyes in electrochemical cells. The first chlorophyll sensitized zinc oxide $(\mathrm{ZnO})$ electrode was synthesized in 1972. For the first time, through electron injection of excited dye molecules into a wide bandgap of semiconductor, photons were converted into electricity [3].The DSSCs, also known as Grätzel cells, were originally co-invented in 1988 by Brian O'Regan and Michael Grätzel at UC Berkeley and were further developed by the aforementioned scientists at EcolePolytechniqueFédèrale de Lausanne (EPFL) till 1991 [4]. DSSC comprises of important parameters which include the working electrode, sensitizer, electrolyte and counter electrode. In order to construct the DSSC, the working electrode is soaked with a sensitizer or a dye which has been extracted and sealed to the counter electrode soaked with a thin layer of electrolyte with the help of a crocodile clip to prevent the leakage of the electrolyte. The cell converts incident light into electrical energy by sensitizing a wide bandgap semiconductor mostly $\mathrm{TiO}_{2}$ to inject a photo-excited electron at the interface between the semiconductor material and the monolayer sensitizer [5]. The nanoporous large-area semiconductors provide anchoring sites for dye molecules acceptor segments for easy electron injection from the generated electron-hole pairs. Charge separation occurs in femtoseconds due to the electron injection from the dye molecules into the conduction band (CB) of the semiconductor [6].

Natural dyes extracted from different biological sources (e.g. anthocyanin, carotenoid, flavonoid, aurone, chlorophyll, tannin, and betalain obtained from fruits, flowers, leaves, seeds, barks, and various parts of plants or other biological sources) have been proposed to be used as sensitizers in DSSCs due to their low cost and environmental friendliness [7], [8], [9], [5], [10], [6].[11] employed Pelargonium hortorum and Pelargonium grandiflorum as sensitizers in their DSSCs and achieved a PCE of $0.065 \%$ and $0.067 \%$, respectively. A major challenge in optimizing DSSC efficiency is the expansion of the absorption range of the photoanode photoactive and/or semiconductor layers [12]. This challenge observed has led researchers to source for methods that would improve the absorption range such as the purification of the extracts, combination of dyes, introducing nanoparticles in the dye and so on. Recently an efficiency of $8.75 \%$ was reported for hybrid dye-titania LASU Journal of Research and Review in Science nanoparticle-based DSSC for superior low temperature by [13].

In this work, different dyes were extracted from the leaves and flowers of Commelino nudiflora and used as sensitizers for the DSSCs. The optical and structural properties of the dyes and the fabricated cells were studied.

\section{MATERIAL AND METHODS}

Leaves and flowers of Commelino nudiflora were collected within the campus of Lagos State University, Ojo, Nigeria. The samples (flowers and leaves) were air dried at room temperature for 4 hours. With the aid of liquidizer, the samples were pulverized. The pulverized samples were soaked separately using a solvent system that comprised of distilled water, methanol and $\mathrm{M} \mathrm{HNO}_{3}$ in ratio 10: 9: 1, respectively. One hundred grams of the pulverized sample was completely submerged in $120 \mathrm{ml}$ of the solvent system and then covered in air tight glass bottle for 24 hours. Extraction occurred after 24 hours and the extract was decanted by evaporation in a water bath at $50 \pm 5^{\circ} \mathrm{C}$ to obtain concentrated extract. The concentrated extracts were stored in dark bottles at room temperature. In order to obtain purified anthocyanin from the extracts, the method in [14] was utilized. The filtered extract was transferred into a separatory funnel and "washed" three times with equal volumes of ethylacetate to remove flavones. The third mixture of the extract and ethylacetate were mixed thoroughly in the separatory funnel and left overnight. The ethylacetate-free layer, containing the partially purified anthocyanin, was obtained. Then, equal volumes of the ethylacetate-free extract and that of $0.5 \%$ neutral lead acetate $\left(\mathrm{Pb}(\mathrm{COO})_{2}\right)$ solution were mixed and kept in the refrigerator at $4^{\circ} \mathrm{C}$ for $48 \mathrm{~h}$ to ensure complete precipitation of anthocyanin. After $48 \mathrm{~h}$, supernatant and dark precipitate (anthocyanin) were obtained, the supernatant was discarded. Consequently, about $5 \mathrm{ml}$ of $0.5 \%$ solution of sulfuric acid was added to the precipitate to remove lead as lead sulfate $\left(\mathrm{PbSO}_{4}\right)$, and the precipitate was simultaneously re-solubilized to give a red solution. The mixture was filtered to remove the $\mathrm{PbSO}_{4}$ and the filtrate. The filtrate was concentrated in a water bath at $50 \pm 5^{\circ} \mathrm{C}$ to obtain the purified anthocyanin.

The $\mathrm{TiO}_{2}$ film was prepared using the methods of [15] and the cells were prepared using the methods of [12]. $\mathrm{TiO}_{2}$ coated glass plate was soaked (facing the dye solution) for $10 \mathrm{~min}$ in each of the various types of extracts (crude and purified), until the white $\mathrm{TiO}_{2}$ paste could not be seen upon viewing the stained film from either side of the glass plate. While the $\mathrm{TiO}_{2}$ electrode was being stained, the counter electrode was made from another piece of ITO glass using the method of 
[12]. The thin carbon layer served as a catalyst for the tri-iodide to iodide regeneration reaction [16]. The solar cells were assembled using the methods of [15]. The photovoltaic parameters of the completed solar cell were taken indoorby using a solar simulator.

\subsection{Theoretical Simulation}

[17] Analyzed theoretically the photoelectrochemical behavior in the DSSC photoelectrode nanostructure. The resulted equation relates the electron transport, electron recombination, and electron photogeneration in thin films DSSC as:

$D \frac{\partial^{2} n(x)}{\partial x^{2}}-\frac{n(x)-n_{0}}{\tau}+\emptyset_{0} \alpha \exp (-\alpha x)=\frac{\partial n}{\partial t}$

where $n(x)$ is the number of excessive electrons photogeneration concentrations at position $x$ in the photoelectrode interface layer, $n_{0}$ represents concentration of electrons below the equilibrium of thedarkconditions, $D$ correspond to the diffusion coefficient of the electron. The parameters $\tau, \emptyset_{0}$ and arepresent the lifetime of the free electrons in the conduction band, the intensity Flux illumination ofphotons and light absorption coefficient of the thin film. In this paper, we use internal parameters in the DSSC $(\Phi, \alpha, m, L, D)$ from previous researches which are written in Table 1[18].

Table 1: Simulation parameters

\begin{tabular}{cc}
\hline Parameter & Published value \\
\hline $\mathrm{L}\left(\mathrm{cm}^{-1} \mathrm{~s}^{-1}\right)$ & $2.2361 \times 10^{-3}$ \\
$\alpha\left(\mathrm{cm}^{-1}\right)$ & 5000 \\
$\mathrm{M}$ & 4.5 \\
$\mathrm{D}\left(\mathrm{cm}^{-1} \mathrm{~s}^{-1}\right)$ & $5.0 \times 10^{-4}$ \\
$n_{0}$ & $10^{16}$ \\
$\tau_{m s}$ & 10 \\
$\emptyset\left(\mathrm{cm}^{-2} \mathrm{~s}^{-1}\right)$ & $1 . \times 10^{17}$ \\
$\mathrm{~d}(\mathrm{~cm})$ & $10 \times 10^{-4}$ \\
$\mathrm{~T}(\mathrm{~K})$ & 300
\end{tabular}

The simulation activity was done with the input of DSSC equation in $m$-file in MATLAB along with the absorption coefficient of each of the extracted dye. The equations related to the simulation model are as follows:

$I_{s c}=\frac{q \delta L \alpha}{1-L^{2} \alpha^{2}}\left[-L \alpha+\tanh \left(\frac{d}{L}\right)+\frac{L \alpha \exp (-d \alpha)}{\cosh \left(\frac{d}{L}\right)}\right]$ (2)

$V_{o c}=\frac{K T m}{q} \ln \left[\frac{L l_{s c}}{q D n_{o} \tanh \left(\frac{d}{2}\right)}+1\right]$

$I=J_{s c}-\frac{q D n_{o}}{2} \tanh \left(\frac{d}{L}\right)\left[\exp \left(\frac{q v}{K T m}\right)-1\right]$

\section{RESULTS AND DISCUSSION}

Figure 1 displays the UV-vis absorption of the extracted crude and purified dyes from the flowers and leaves. It is observed that all the extracts show similar absorption pattern although, the extracts (crude and purified) from the leaves indicate a better absorption in comparison with the flower extracts. The crude extracts for both flower and leaves show similar absorption pattern with prominent absorption I the visible region. In similar vein, after the purification of the crude extracts it is observed that there is a reduction in the absorbance due to the fact that other compounds which contributed to the absorption could have been washed out. The purified leaves extract shows a better absorption at approximately $400 \mathrm{~nm}$. The shift in the absorption pattern of the extracts is mainly due to the chemical structure of the dye [19].Consequently, broader absorption spectra are observed for the purified extracts which are probably due to the fact that the anthocyanins isomers have not been isolated. The results of the absorbance showed that the dye solutions can be used as photosensitizers for DSSC because they appear to absorb in the visible region. Similarly, [20] posits that the chemical adsorption of the dyes results due to the bond formation with the $\mathrm{TiO}_{2}$. Also, Figure 2 displays the absorbance curve of crude extracts of flower and leaves at $\mathrm{pH}$ 1.25. A similar curve pattern is observed for both extracts though the leaves extract shows a better absorption of the incident light.

Different DSSCs were prepared using $\mathrm{TiO}_{2}$ mesoporous layers with crude and purified samples used as sensitizer. The current density voltagecharacteristics of these cells are shown in Figures 3 to 6 . The overall efficiency $(\eta)$ was calculated using the following equations:

$$
F F=\frac{V_{m} \times J_{m}}{V_{o c} \times l_{s c}}
$$

$\eta=\frac{V_{m} \times J_{s c} \times F F}{P_{\text {in }}} \times 100 \%$

where $P_{\text {in }}$ is the radiation power incident on the cell, $J_{\text {sc }}$ is short-circuit current density at zero voltage, $V_{o c}$ is the open-circuit voltage at zero current density, $\mathrm{Jm}$ is the maximum current density, $V_{m}$ is maximum voltage, and FF is the fill factor. A summary of the photovoltaic parameters is obtained from Figures 3 to 6 and presented in Table 2. It can be observed from the crude extracts that the flower extract exhibits a higher current density when compared to the leaves extract. This increase in Jsc resulted in a better PCE for the crude flower extract. It is observed that the purified extract of the leaves exhibits an improved short circuit current in comparison to the flower extract. This improvement in Jsc is probably due to the proper dissociation and collection of the carriers at their respective electrodes. Similarly, the improvement in Jsc could be linked to the improved absorbance observed in Figure 1 for the extracts. Also, an enhanced PCE is observed for the crude (flower and leaves) extract. The power conversion efficiency obtained from this study is in comparison to what is obtained in literature. Also, the low Jsc and PCE obtained as seen in Table 1 is due to the limited range of incident light absorption of the extracts adsorbed on $\mathrm{TiO}_{2}$. It was also noticed from the results of [21] that a high concentration of chlorophyll in the extracts leads 
to low photovoltaic performance due to dye aggregation on the $\mathrm{TiO}_{2}$ film, which probably leads to low performance due to concentration quenching.It is observed that the Jsc for the leaves crude extract is lower in comparison to the flower crude extract. This reduction in Jsc is attributed to the low dissociation of excitons though the leaves crude extract shows a better absorbance. The difference in dye structures and the rate of charge injection into the $\mathrm{TiO}_{2}$ conduction band is responsible for the difference in the current densities as observed in this work [22]. Subsequently, [23] and [24] established that the performance of DSSC depends on the properties of solvent used such as polarity, temperature, dye combination and acidity. Also, the polarity of the extraction solvent tends to affect the solubility and therefore the adsorption behavior between the extracted dyes bonding into $\mathrm{TiO}_{2}$ surface, thereby affecting cell performance [25]. The PCEs obtained are observed to be lower to silicon based solar cells and this can be attributed to the size of the barriers found in DSSC. Similarly, the dyes are assumed to be very unstable and oxidize easily when exposed to air [27]. Consequently, in order to determine the effectiveness of the extracted dyes (crude and purified), a simulation of the photovoltaic performance was evaluated using equations 2 to 4 . Figures $7-10$ display the current density - voltage curve for the simulated devices and values summarized in Table 3 , it is observed that the simulated devices show low performance in comparison to the fabricated devices (Table 2). The low performance of the simulated devices could be attributed to the experimental data (absorption coefficient) of the extractsthat has been introduced into the model. Although, the performance of the simulated devices is low, it is observed that the leaves extract (crude and purified) shows a better performance among the simulated devices. This improvement in performance of simulated devices can be attributed to the large absorbance value, the natural dye will absorb the light with a large wavelength. Similarly, if the wavelength absorbed becomes larger, then the energy of the photon used to excite the electron to the conduction band requires less energy [10].

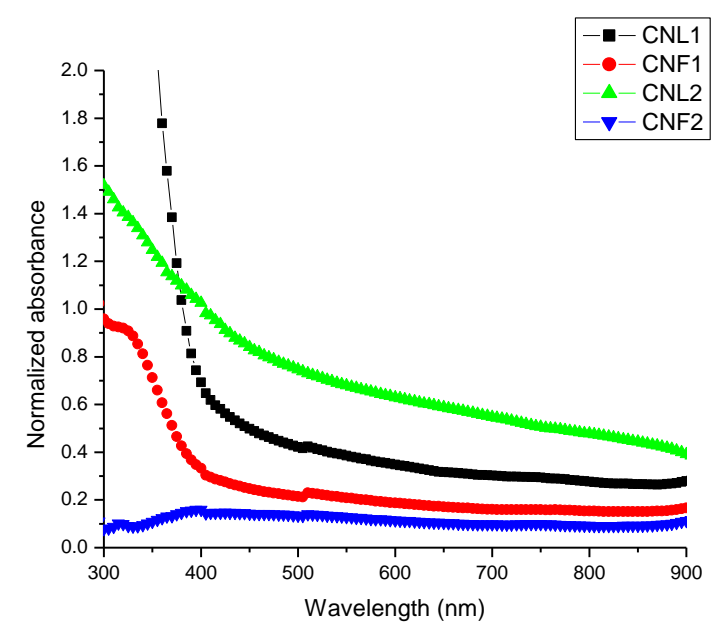

Fig. 1: Absorbance graph of crude and purified extracts for leaves and flowers

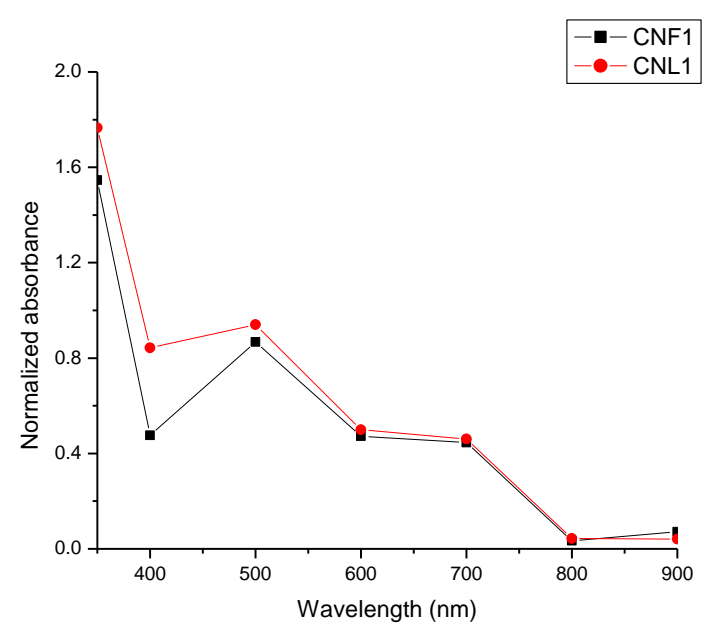

Fig. 2: Absorbance curve for crude extract of leaves and flower at $\mathrm{pH} 1$.

Table 2: Photovoltaic parameters for the fabricated solar cells

\begin{tabular}{ccccc}
\hline Sample & J sc $\left._{\text {sc }} \mathbf{m} / \mathbf{c m}^{2}\right)$ & $\mathrm{V}_{\text {oc }}(\mathbf{m V})$ & FF & PCE $(\%)$ \\
\hline CN L1 & 0.00375 & 1.99981 & 0.62 & 0.00372 \\
CN F1 & 0.00393 & 2.00007 & 0.62 & 0.00389 \\
CN L2 & 0.00415 & 2.0031 & 0.39 & 0.00194 \\
CN F2 & 0.00237 & 2.00055 & 0.64 & 0.00243 \\
\hline
\end{tabular}

${ }^{*}$ Crude leaves (CN L1), Crude flower (CN F1), Purified leaves (CN L2) and Purified flower (CN F2) extracts. 


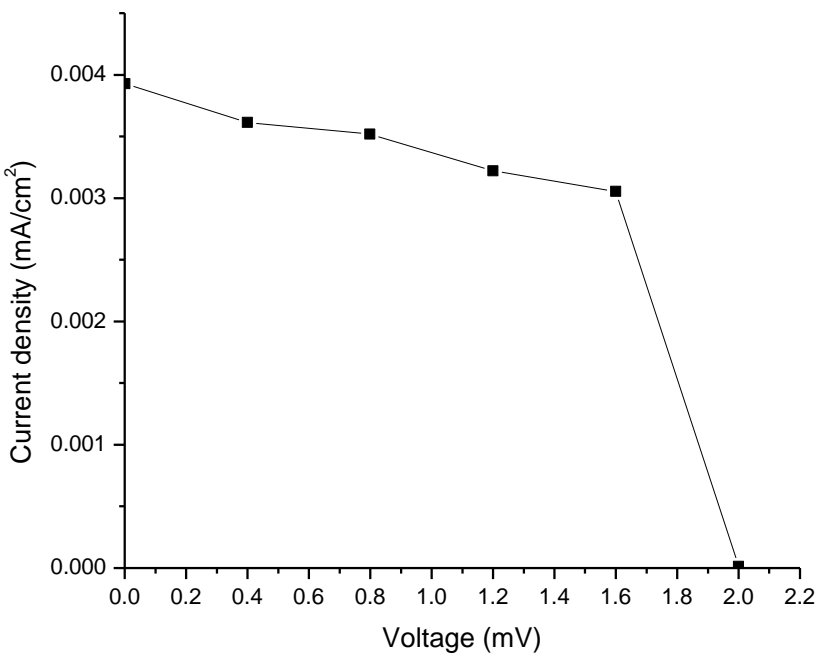

Fig.3: Current density - voltage curve for flower crude extract

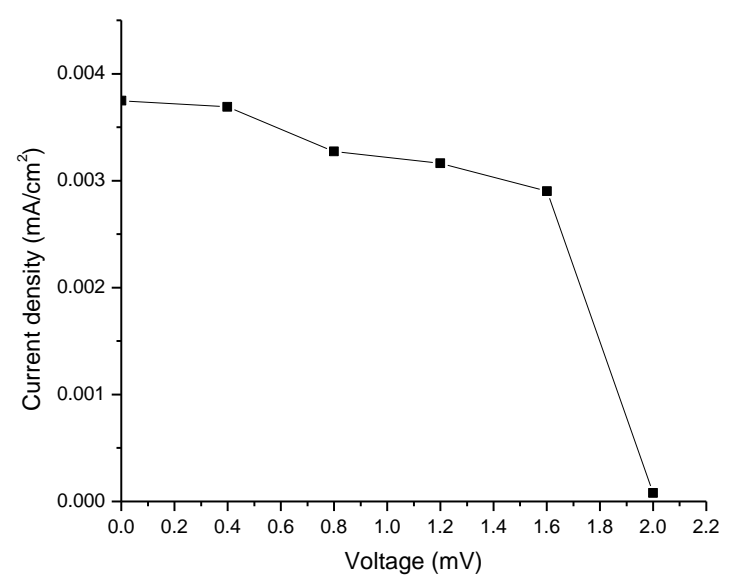

Fig.4: Current density - voltage curve for leaves crude extract

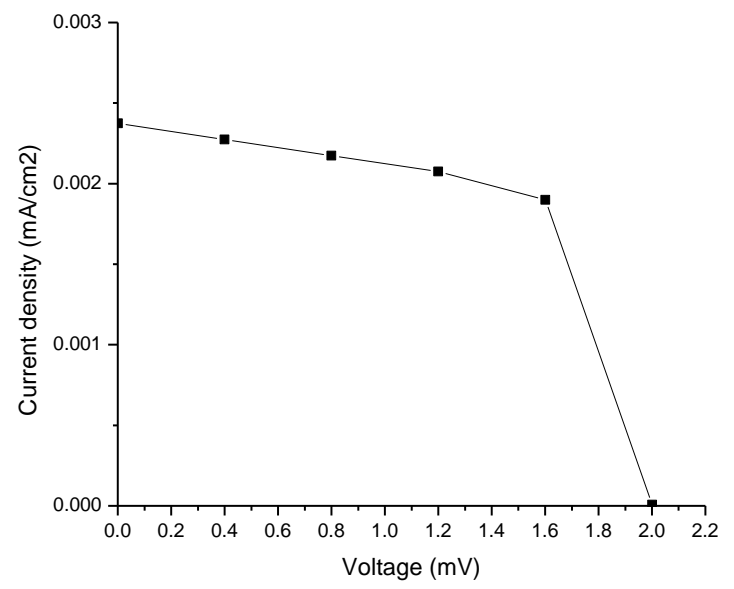

Fig.5: Current density - voltage curve for flower purified extract

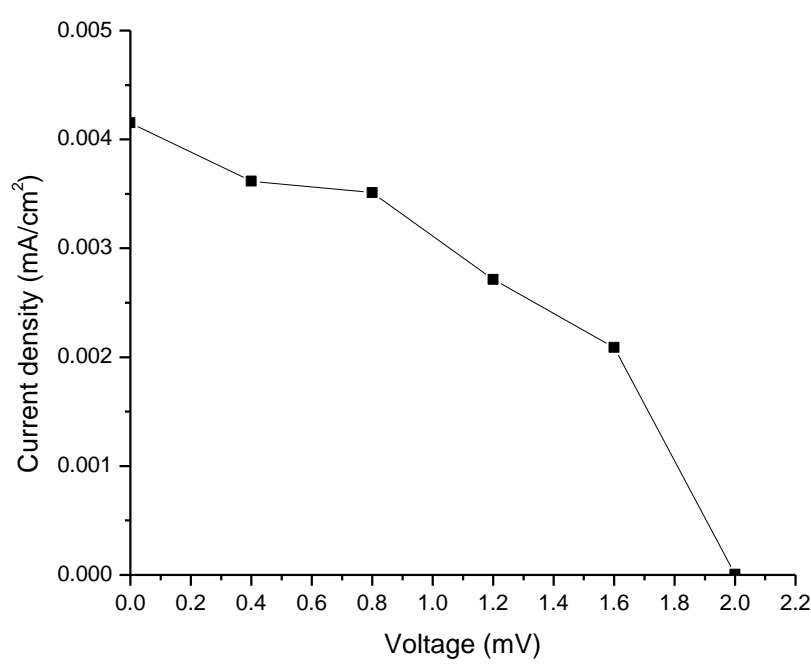

Fig.6: Current density - voltage curve for leaves purified extract

Table 3: Photovoltaic parameters for the simulated devices

\begin{tabular}{cccc}
\hline Sample & $\mathbf{J}_{\mathrm{sc}}\left(\mathbf{m A} / \mathbf{c m}^{2}\right)$ & $\mathbf{V}_{\text {oc }}(\mathbf{m V})$ & $\mathrm{PCE}(\%)$ \\
\hline CN L1 & 1.80 & 0.73 & 0.00233 \\
CN F1 & 5.62 & 0.57 & 0.00071 \\
CN L2 & 9.82 & 0.65 & 0.00124 \\
CN F2 & 1.25 & 0.41 & 0.00016 \\
\hline
\end{tabular}

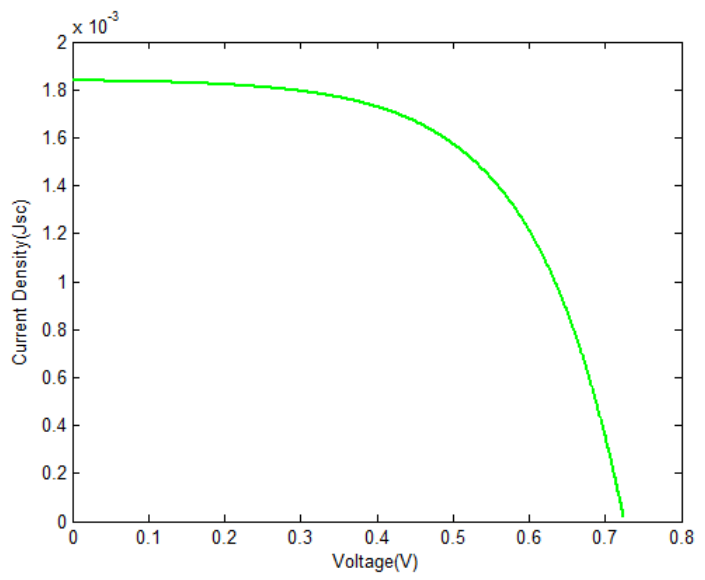

Fig. 7: Simulated J - V curve for crude leaves extract

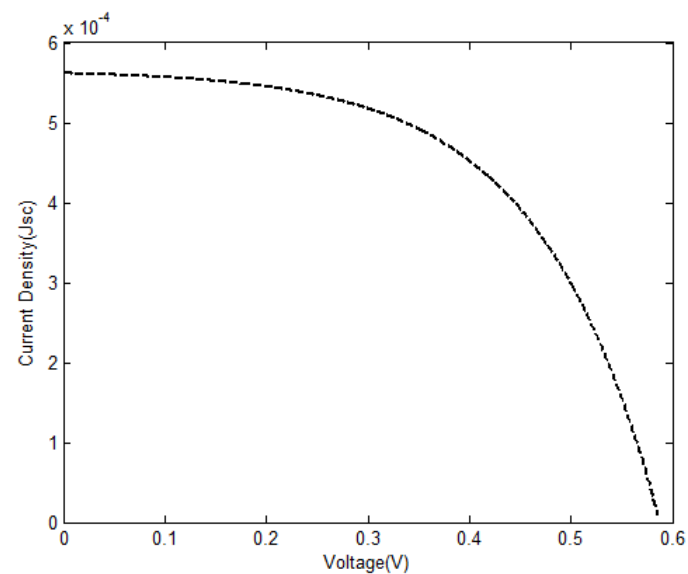


Fig. 8: Simulated J - V curve for crude flower extract

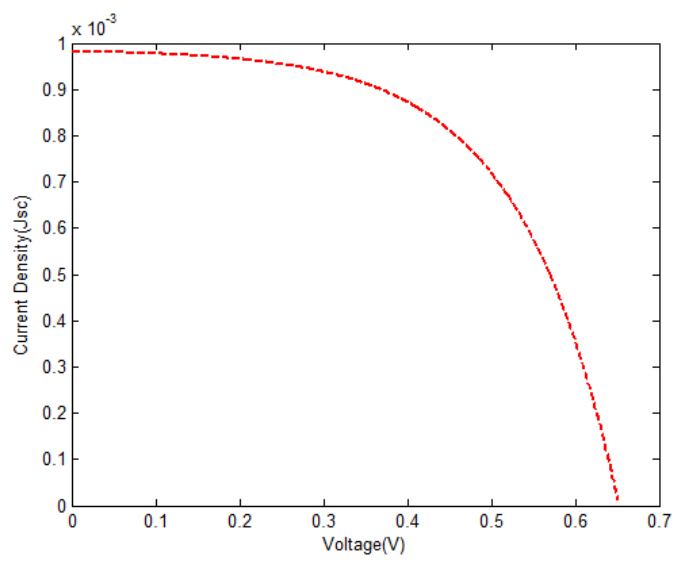

Fig. 9: Simulated J - V curve for purified leaves extract

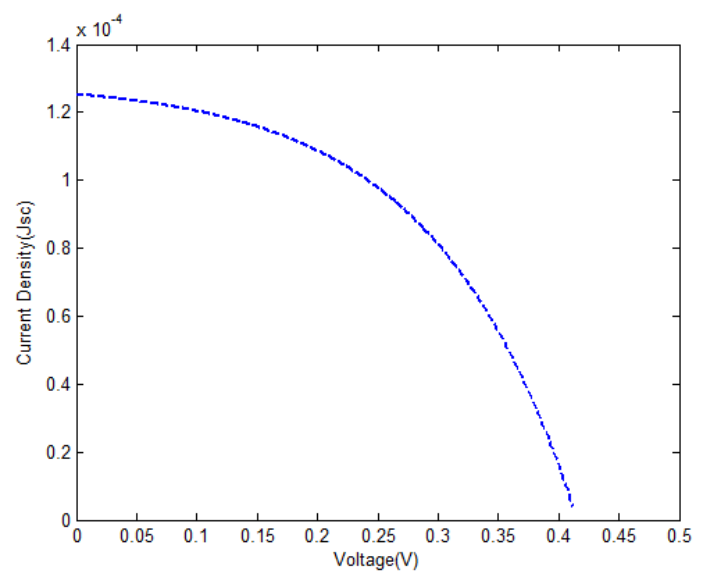

Fig. 10: Simulated J - V curve for purified flower extract

\section{CONCLUSION}

The main aim of this study was to determine the performance of fabricated DSSCs based on the crude and purified extracts from the leaves and flower of Commelinonudiflora. The crude and purified extracts were safely extracted using simple methods. The extraction, preparation and photovoltaic performance of the DSSCs were optimized. Also, the optical and electrical properties of the dyes were studied. Among the dyes extracted, the crude extract of the flower gave the highest efficiency of $0.00233 \%$. In similar vein, it was noticed that the extracts (crude and purified) from the leaves exhibited better absorption as observed from the absorbance graphs (Figure 1). It can be noted from the values obtained from the simulations that the dyes are appropriate to be used as sensitizers in the fabrication of solar cells due to the absorbance and PCE obtained. In similar vein, more work needs to be done in order to attain the best possible performance from these natural dyes such as improving its stability and reducing degradation.

\section{ACKNOWLEDGEMENTS}

The authors acknowledge the funding provided by TETFUND, Lagos State University.

\section{COMPETING INTERESTS}

The authors declare no competing interest with regards the research embarked upon.

\section{AUTHORS' CONTRIBUTIONS}

Boyo, A. O, Oseni, S. O., Kesinro, R. O and Ibrahim, $\mathrm{O}$. A designed the study and wrote the protocol for the experiment including identification, extraction and characterization of dye samples. Akingbade, F. S., Oladepo, A. M. and Okafor, P managed the literature searches and compilation. Abiola, A. O managed the simulation of the experiment. All authors read and approved the final manuscript.

\section{References}

1. Snaith, H. J. (2010). Estimating the Maximum Attainable Efficiency in Dye- Sensitized Solar Cells. AdvFunct Mater, 20:13-19.

2. Frank, A. J., Kopidakis, N., \& De Lagemaat, J. V. (2004). Electrons in nanostructured $\mathrm{TiO}_{2}$ solar cells: Transport, recombination and photovoltaic properties. Coord Chem Rev 248:1165-1179.

3. Tributsch, H., and Calvin, M. (1971). Electrochemistry of excited molecules: Photoelectrochemical reactions of chlorophylls. PhotochemPhotobiol 14:95-112.

4. O'Regan, B., and Grätzel, M. (1991). A lowcost, high-efficiency solar-cell based on dye sensitized colloidal $\mathrm{TiO}_{2}$ films. Nature, 353: 737-740.

5. Molaeirad, A., Janfaza, S., Karimi-Fard, A., and Mahyad, B. (2015). Photocurrent generation by adsorption of two main pigments of Halobacteriumsalinarum on $\mathrm{TiO}_{2}$ nanostructured electrode. BiotechnolApp/Biochem, https://doi.org/ 10.1002/bab.1244.

6. Richhariya, G., Kumar, A., Tekasakul, P., \& Gupta, B. (2017). Natural dyes for dye sensitized solar cell: A review. Renew Sustain Energy Rev. https://doi.org/10.1016/j. rser.2016.11.198.

7. Kumara, N.T. R. N., Lim, A., Lim, C. M., Petra, M. I., \& Ekanayake, P. (2017). Recent progress and utilization of natural pigments in dye sensitized solar cells: A review. Renew Sustain Energy Rev. https://doi.org/10.1016/i.rser.2017.04.075. 
8. Adedokun, O., Titilope, K., \&Awodugba, A. O. (2016). Review on natural dye-sensitized solar cells (DSSCs). Int $J$ EngTechnol IJET. https://doi.org/10.19072/ijet.96456.

9. Hug, H., Bader, M., Mair, P., \&Glatzel T. (2014). Biophotovoltaics: natural pigments in dye-sensitized solar cells. Appl Energy. https://doi.org/10.1016/j.

apenergy.2013.10.055.

10. Karakuş, M. O., Koca, I., Er, O., and H. Çetin, H. (2017). Dye ingredients and energy conversion efficiency at natural dye sensitized solar cells. Optical Materials, 66: 552-558.

11. Gratzel, M. (2004). Conversion of sunlight to electric power by nanocrystalline dyesensitized solar cells. J PhotochemPhotobiolAChem, https://doi.org/10.1016/j.jphotochem.2004.02.0 23.

12. Costa, R., Kunzmann, A., Valero, S. E., Sepúlveda, A., Rico-Santacruz, M., Lalinde, E. R., Berenguer, J., García-Martínez, J. M., Guldi, D., and Serrano, E. D. (2018) Hybrid dye-titania nanoparticles for superior lowtemperature dye-sensitized solar cells. Adv Energy Mat 8:121-212.

13. Taofeek, O. A., Nasir, A. S., Musa, T. Y., Adenike, T. O., Musbau, A. A., and Joseph, I. O. (2011). Antioxidant and drug detoxification potentials of Terminaliacatappa anthocyanin extract. Drug Chem. Toxicol. 34(2):109-115.

14. Boyo, A.O., Okafor, P., Abdulsalami, I. O., Oluwole, S., and Boyo, H. O. (2013). Application of Terminaliacatappa and leaves of Azardirachtaindicacalyxes as sensitizers in Dye-sensitized solar cells. Int. J. Eng. Res. Dev. 8(12):38-42.

15. Södergren, S., Hagfeldt, A., Olsson, J., and Lindquist, S. E. (1994). J. Phys. Chem 98:5552.

16. Habieb, A. M., Irwanto, M., Alkian, I., Sya'diyah, K., Widiyandari, H., and Gunawan, V. (2018). Dye sensitized solar cell simulation performance using MATLAB. IOP conference series: Journal of Physics: Conference series, 1025: 012001.

17. Danladi, E., Ezeoke, J., Ahmad, M. S., Danladi, E., Sarki, S. H., Ishaya, I., and Gyuk, P. M. (2016). Physical Science International Journal 10 (2) 1-7.

18. Godibo, D. J., Anshebo, S. T., \&Anshebo, T. Y. (2015). Dye sensitized solar cells using natural pigments from five plants and quasisolid-state electrolyte. Journal Braz. Chem. Soc, 26(1), 92 - 101.

19. Moustafa, K. F., Rekaby, M., El Shenawy, E. T., and Khattab, N. M. (2012). JASR 8 43934404

20. Lim, A., Damit, D.-N. F. B., \&Ekanayak, P. (2015). Tailoring of extraction solvent of Ixora coccinea flower to enhance charge transport properties in dye-sensitized solar cells. lonics, 21, 2897-2904.

21. Wark-koyo, E. A. S. (2011). The solvent effectiveness on extraction process of seaweed pigment. MakaraTeknologi, 15, 5-8.

22. Wongcha-ree, K., Meeyo, V., \&Chavadej, S. (2007). Dye-sensitized solar cells using natural dyes extracted from rosella and blue pea flowers. Solar Energy Materialsand Solar Cells, 91, 566-571.

23. Sreekala, C. O., Jinchu, I., Sreelatha, K. S., Janu, Y., Prassad, N., Kumar, M., et al. (2012). Influence of solvents and surface treatment on photovoltaic response of DSSC based on natural curcumin dye. IEEE Journal of Photovoltaics, 2, 312-319.

24. Syafinar, R., Gomesh, N., Irwanto, M., Fareq, M., and Irwan, Y. M. (2015). Potential of Purple Cabbage, Coffee, Blueberry and Turmeric as Nature Based Dyes for Dye Sensitized Solar Cell (DSSC). vol 79 (Elsevier B.V.)

25. Hwang, D. K., Lee, B., and Kim, D. H. (2013). Efficiency enhancement in solid dye-sensitized solar cell by three-dimensional photonic crystal. RSC Advances, 3: 9, 3017-3023. 